\title{
Relationship between straight and curved walking abilities among inpatients in the subacute phase according to walking independence level
}

\author{
Kazuya Fujii ${ }^{a, b}$, Masaki Kobayashi ${ }^{b}$, Miyuki Sato ${ }^{b}$, Yasuyoshi Asakawa ${ }^{a}$ \\ aDepartment of Physical Therapy, Geriatrics Research Institute and Hospital, Maebashi, Japan \\ ${ }^{\mathrm{b}}$ Department of Physical Therapy, Graduate School of Human Health Sciences, Tokyo Metropolitan University, Arakawa, Japan
}

Objective: This study was performed to examine differences in the association between straight and curved walking abilities of inpatients in the subacute phase and walking independence level.

Design: Cross-sectional study.

Methods: Subjects were divided into an independent group and a supervised group ( $\mathrm{n}=10$ each) by walking independence level within the ward decided by physical therapists. Inclusion criteria comprised the ability to ambulate independently within the ward, regardless of the use of walking aids. Straight walking abilities (walking velocity, stride length, and cadence) were evaluated using the 5-meter walk test. Curved walking abilities were evaluated using the Figure-of- 8 Walk Test (F8W) and the 3-meter zigzag walk test $(3 \mathrm{ZW})$. Differences in associations between straight and curved walking abilities of inpatients were examined by calculating correlation coefficients between straight and curved walking abilities.

Results: Age, walking velocity, stride length, F8W and 3ZW varied markedly between independent and supervised groups. In the independent group, F8W and 3ZW correlated significantly with walking velocity and cadence $(p<0.05)$. In the supervised group, F8W correlated significantly with walking velocity and stride length $(p<0.05)$, but $3 \mathrm{ZW}$ did not correlate significantly with straight walking abilities.

Conclusions: The association between straight and curved walking abilities varied between inpatients who could ambulate independently and inpatients requiring supervision for ambulating. These differences may depend on skill on straight and curved walking abilities. There is a possibility that curved walking exercise is necessary for supervised group.

Key Words: Ambulation independence level, Curved walking ability, Inpatients

\section{Introduction}

The straight walk test is frequently used as a general index to assess walking abilities. Walking velocity and step length measured using the straight walk test have been shown to decrease with age [1]. Although the straight walk test is simple, convenient, and usable for clinical assessment, the ability to walk on a straight path (straight walking ability) in the absence of environmental or situational changes is rarely needed in daily living [2]. In actual daily settings and living envi- ronments, the ability to walk on curved paths (curved walking ability), such as walking around tables, walking while avoiding obstacles, and walking along the corner, is more frequently applicable [2]. When walking on a curved path, the center of gravity reportedly shifts medially to the lower limbs, consequently prolonging the stance phase on that side and increasing step length on the lateral side of the lower limbs [2], but such adaptation to curved paths is difficult for individuals with mobility problems [3]. In this respect, assessment of the curved walking ability of inpatients with

Received: 12 February, 2018 Revised: 9 March, 2018 Accepted: 11 March, 2018

Corresponding author: Kazuya Fujii (ORCID http://orcid.org/0000-0002-0816-4072)

Department of Physical Therapy, Geriatrics Research Institute and Hospital, 3-26-8 Ootomo-Machi, Maebashi 371-0847, Japan

Tel: 81-27-253-3311 Fax: 81-27-252-7575 E-mail: fuji-kazuya1@ed.tmu.ac.jp

(c) This is an Open-Access article distributed under the terms of the Creative Commons Attribution Non-Commercial License (http://creativecommons.org/licenses/ by-nc/4.0) which permits unrestricted non-commercial use, distribution, and reproduction in any medium, provided the original work is properly cited.

Copyright $@ 2018$ Korean Academy of Physical Therapy Rehabilitation Science 
mobility problems may also be necessary.

Hess et al. [3] developed the Figure-of-8 Walk Test (F8W) to assess curved walking ability. The $\mathrm{F} 8 \mathrm{~W}$ requires a person to walk a figure-of- 8 around 2 cones placed 5 feet apart. The $\mathrm{F} 8 \mathrm{~W}$ is designed to measure walking abilities in daily living, and has some merit: (1) the task is readily recognized by name alone; (2) the pattern consists of walking on curved paths, clockwise and counterclockwise, with straight-path walking between the curved paths; (3) alternation between straight and curved paths requires switching motor strategies, including biomechanical and movement control adjustments; and (4) motor planning is needed to navigate the straight and curved paths. Similarly, Masuda et al. [4] developed the 10-meter zigzag walk test to simulate home environments and focus on the frequent turns associated with indoor falls. The 3-meter zigzag walk test (3ZW) based on this is also available [5]. Both tests facilitate more practical assessment of curved walking ability under simulated daily living environments.

In a previous study examining community-dwelling older adults, strong to moderate correlations were observed between straight walking ability (walking velocity) and F8W results $[3,6]$. In addition, physical functions such as lower-limb muscle strength and range of motion [6], and activities of daily living (ADL) [3] were associated with both straight walking ability and F8W results, while walking-related self-efficacy [3], perceived walking difficulties [3], step width coefficient of variation [3], and asymmetry of leg strength [6] were only associated with F8W results. Among primary-care patients, declines in straight walking ability and F8W results increase the risk of falls [7]. On the other hand, among community-dwelling older adults, the $3 \mathrm{ZW}$ has been shown to be associated with the walking velocity, and cut-off values for this test for predicting falls have also been calculated [5]. However, studies to examine inpatients using the $\mathrm{F} 8 \mathrm{~W}$ or $3 \mathrm{ZW}$ have not been conducted, and the relationship between straight and curved walking ability has remained unclear.

The purpose of the present study was to divide inpatients into two groups based on ambulation independence level, and to compare associations between ambulation independence level and straight and curved walking abilities of inpatients. We hypothesized that straight and curved walking abilities of inpatients were significantly different with ambulation independence levels. In the inpatients who have absolutory high walking abilities, straight walking ability would correlate strongly with curved walking ability, on the other hand in the inpatients who have absolutory poor walking abilities, straight walking ability is weak or moderate correlated with curved walking ability. We predicted that difference of skill on straight and curved walking abilities is associated with relationships between straight and curved walking abilities.

\section{Methods}

\section{Participants}

Twenty inpatients in the subacute phase were studied based on the following inclusion and exclusion criteria. Inclusion criteria comprised the ability to ambulate independently within the ward, regardless of the use of walking aids. Exclusion criteria comprised: 1) presence of dementia or severe higher brain dysfunction; or 2) difficulty comprehending the study objective, walking courses, or instructions. Inpatients were divided into two groups based on ambulation independence level within the ward decided by physical therapists: an independent group (inpatients who were able to ambulate independently within the ward with or without using a cane) and a supervised group (inpatients able to ambulate independently within the ward using a walker, but requiring supervision by ward staff when walking with or without a cane).

This study was approved by the Institutional Review Board at Geriatrics Research Institute and Hospital (approval No. 38), and all participants provided written informed consent to participate.

\section{Straight walking ability}

Straight walking ability was assessed using the 5-meter walk test [8]. The test was conducted on an 11 meter course, consisting of a 5 meter section for measurement and 3 meter of path before and after the measurement section. Patients started to walk at their own timing and usual walking velocities, and the time and number of steps needed to walk the 5 meter section was measured to calculate 5 meter walking velocity $(\mathrm{m} / \mathrm{s})$, stride length $(\mathrm{m})$, and cadence (steps $/ \mathrm{min})$.

\section{Curved walking ability}

Curved walking ability was assessed using the F8W [3] (time needed) and 3ZW [5] (time needed).

\section{Figure-of-8 Walk Test}

The F8W [3] is conducted on a figure 8-shaped course, consisting of straight and curved sections around 2 cones 
placed 5 feet apart. This test has been shown to be highly reliable, with high test-retest reliability (intra-class correlation coefficient $[\mathrm{ICC}]=0.783)$ and inter-rater reliability $(\mathrm{ICC}=$ 0.95-0.993). Following the original instruction, patients started to walk at their own pace from the center between the 2 cones, and the time needed to return to the center between the 2 cones was measured. Considering possible influences on motor intentions, starting or finishing points were not marked with tape, with the course only marked using the 2 cones to indicate turning points. Times were measured at the usual walking velocities of each patient.

\section{Three meter Zigzag Walk Test (3ZW)}

The 3ZW [5] is a test combining walking and turns, and has shown high inter-rater reliabilities (ICC $=0.97$ and 0.94) when involving community residents with and without a history of falls, respectively [5]. Following the original instruction, in the present study, testing was conducted on a 3 meter zigzag course, with marked starting and finishing points and 4 poles placed at intervals of $60 \mathrm{~cm}$ from the starting point to the finishing point. Patients walked the course at their usual walking velocity to measure the time required.

Table 1. Characteristics of independent and supervised groups

$(\mathrm{N}=20)$

\begin{tabular}{|c|c|c|}
\hline Characteristic & $\begin{array}{l}\text { Supervised } \\
(\mathrm{n}=10)\end{array}$ & $\begin{array}{l}\text { Independent } \\
\quad(\mathrm{n}=10)\end{array}$ \\
\hline Age (y) & $81.6(4.9)(74-89)$ & $72.1(5.4)(62-83)$ \\
\hline \multicolumn{3}{|l|}{ Sex } \\
\hline Male & 2 & 5 \\
\hline Female & 8 & 5 \\
\hline \multicolumn{3}{|l|}{ Disease } \\
\hline $\begin{array}{l}\text { Lower-limb joint } \\
\text { disease }\end{array}$ & 5 & 3 \\
\hline $\begin{array}{l}\text { Cerebrovascular } \\
\text { diseases }\end{array}$ & 3 & 5 \\
\hline $\begin{array}{l}\text { Vertebral/spinal cord } \\
\text { diseases }\end{array}$ & 2 & 2 \\
\hline \multicolumn{3}{|c|}{ Walking device (ward walking) } \\
\hline Walker & 10 & 0 \\
\hline T-shaped handle cane & 0 & 5 \\
\hline No & 0 & 5 \\
\hline \multicolumn{3}{|c|}{ Walking device (examination) } \\
\hline Walker & 0 & 0 \\
\hline T-shaped handle cane & 6 & 4 \\
\hline No & 4 & 6 \\
\hline
\end{tabular}

Values are presented as mean (SD) (min-max) or number only.

\section{Statistical analysis}

For statistical analysis, IBM SPSS Statistics ver. 21.0 (IBM Co., Armonk, NY, USA) was used. To compare age and straight/curved walking abilities between independent and supervised groups, the unpaired t-test and MannWhitney U-test were used. The association between straight and curved walking abilities was examined by calculating Pearson's product-moment correlation coefficient and Spearman's rank correlation coefficient. The significance level was set at $5 \%$.

\section{Results}

A total of 20 inpatients (mean \pm SD age $=76.9 \pm 7.01$ years) were divided into an independent group $(n=10)$ and a supervised group ( $\mathrm{n}=10$; Table 1$)$.

In comparing groups, the supervised group was significantly older than the independent group $(p<0.05)$. Walking velocity, stride length, F8W, and $3 \mathrm{ZW}$ results were significantly greater in the independent group than in the supervised group $(p<0.05)$. No significant difference in cadence was apparent ( $p=0.237$; Table 2$)$.

On examining associations among walk test results in the independent group, F8W time correlated significantly with walking velocity $(\mathrm{r}=-0.815, p<0.05)$ and cadence $(\mathrm{r}=-0.827$, $p<0.05)$. Similarly, 3ZW time showed correlations with walking velocity $(\mathrm{r}=-0.780, p<0.05)$ and cadence $(\mathrm{r}=$ $-0.732, p<0.05)$. In the supervised group, F8W time correlated significantly with walking velocity $(\mathrm{r}=-0.742$, $p<0.05)$ and stride length $(\mathrm{r}=-0.729, p<0.05)$, while $3 \mathrm{ZW}$ time did not show any correlations with straight walking

Table 2. Comparison of independent and supervised groups

\begin{tabular}{lccc}
\hline \multicolumn{1}{c}{ Variable } & $\begin{array}{c}\text { Supervised } \\
(\mathrm{n}=10)\end{array}$ & $\begin{array}{c}\text { Independent } \\
(\mathrm{n}=10)\end{array}$ & $p$-value \\
\hline Age (y) & $81.6(4.9)$ & $72.1(5.4)$ & $0.001^{\mathrm{a}}$ \\
5MWT & & & \\
$\quad$ Walking velocity (m/s) & $0.74(0.16)$ & $1.04(0.26)$ & $0.008^{\mathrm{a}}$ \\
Stride length (m) & $0.76(0.16)$ & $0.97(0.14)$ & $0.008^{\mathrm{a}}$ \\
Cadence (steps/min) & $117.5(10.8)$ & $127.1(21.1)$ & $\mathrm{NS}^{\mathrm{a}}$ \\
F8W (s) & $12.7(2.7)$ & $8.9(3.0)$ & $0.013^{\mathrm{b}}$ \\
3ZW (s) & $9.5(1.7)$ & $6.4(2.7)$ & $0.010^{\mathrm{b}}$ \\
\hline
\end{tabular}

Values are presented as mean (SD).

5MWT: 5-meter walk test, NS: not significant, F8W: Figure-of-8 Walk Test, 3ZW: 3-meter zigzag walk test.

${ }^{\mathrm{a}}$ Unpaired t-test, ${ }^{\mathrm{b}}$ Mann-Whitney U-test. 
Table 3. Association among walk test results in independent and supervised groups $(\mathrm{N}=20)$

\begin{tabular}{|c|c|c|c|c|}
\hline \multirow{2}{*}{ Variable } & \multicolumn{2}{|c|}{ Independent $(\mathrm{n}=10)$} & \multicolumn{2}{|c|}{ Supervised $(\mathrm{n}=10)$} \\
\hline & F8W (s) & $3 Z W(s)$ & F8W (s) & $3 Z W(s)$ \\
\hline \multicolumn{5}{|l|}{$5 \mathrm{MWT}$} \\
\hline Walking velocity $(\mathrm{m} / \mathrm{s})$ & $-0.815^{\mathrm{a},{ }^{* *}}$ & $-0.780^{\mathrm{a},{ }^{* *}}$ & $-0.742^{\mathrm{a}, *}$ & $-0.375^{\mathrm{a}}$ \\
\hline Stride length (m) & $-0.355^{\mathrm{a}}$ & $-0.464^{\mathrm{a}}$ & $-0.729^{\mathrm{b}, *}$ & $-0.509^{\mathrm{a}}$ \\
\hline Cadence (steps/min) & $-0.827^{\mathrm{a},{ }^{* *}}$ & $-0.732^{\mathrm{a}, *}$ & $0.244^{\mathrm{b}}$ & $0.030^{\mathrm{a}}$ \\
\hline
\end{tabular}

Values are presented as correlation coefficient.

F8W: Figure-of-8 Walk Test, 3ZW: 3-meter zigzag walk test, 5MWT: 5-meter walk test.

${ }^{\mathrm{a}}$ Spearman's rank correlation coefficient, ${ }^{\mathrm{b}}$ Pearson's product-moment correlation coefficient. ${ }^{*} p<0.05,{ }^{* *} p<0.01$.

abilities (Table 3).

\section{Discussion}

The present study compared associations between straight (walking velocity, stride length, and cadence) and curved (F8W and 3ZW results) walking abilities of two groups with different levels of walking independence. We considered that examining differences between supervised group and independent group was might be useful to increase ambulation independence level of supervised group within the ward. Therefore, we divided inpatients into the supervised group and independent group.

The independent group included inpatients who had absolutory high walking ability and could ambulate independently within the ward with use of a cane or without walking devices. On the other hand, the supervised group included inpatients who had poor walking ability, requiring supervision by ward staff when walking with a cane, and they needed a walker to be able to ambulate independently within the ward. Significant differences in walking velocity, stride length, F8W and 3ZW results were evident between the independent and supervised groups.

The independent group was skilled in both straight and curved walking abilities, and there were strong correlations between straight walking ability and curved walking abilities (F8W and 3ZW). The supervised group was skilled in straight ability but not in curved walking ability (especially turns in walking), and there were no correlations between straight walking ability and $3 \mathrm{ZW}$. The relationship between straight and curved walking abilities thus differed by walking independence level. In the independent group, F8W results were associated with walking velocity and cadence. In the supervised group, F8W results were associated with walking velocity and stride length. A previous study correlated F8W time with walking velocity $[3,6]$, and the F8W includes a straight walking path [3]. F8W time was thus associated with walking velocity in both groups. In the independent group, F8W time was associated with cadence. The F8W involves alternating between straight and curved paths and thus requires switching motor strategies, including biomechanical and movement control adjustments [3]. The independent group was able to switch motor strategies and perform F8W without significantly decelerating walking velocity when the walking path changed from straight to curved. As a result, F8W time correlated with cadence. On the other hand, the supervised group was not as able to switch motor strategies, and therefore decelerated walking velocity when the walking path changed from straight to curved. To complete the F8W faster, the supervised group might thus have taken longer strides. As a result, F8W time correlated with stride length in the supervised group, but not with cadence.

In the independent group, 3ZW was associated with walking velocity and cadence, but $3 \mathrm{ZW}$ did not correlate with straight walking ability in the supervised group. The $3 Z \mathrm{~W}$ is a curved walking test that includes frequent turns in walking and has fewer components of straight walking. Consequently, relationships between $3 \mathrm{ZW}$ and straight walking ability differed with groups.

Accordingly, in the supervised group, improvement of curved walking ability was not related to improvement of straight walking ability. Therefore, there is a possibility that curved walking exercise is necessary for the supervised group to increase ambulation independence level within the ward.

A limitation of this study was that relationships between straight and curved walking ability were examined only us- 
ing quantitative assessments such as the time and number of steps subjects needed to perform tests, and were not examined by kinematic assessment. In future studies, more detailed information (i.e., muscle power, balance ability or ADL ability level) will be essential and examination of subjects who show asymmetric walking such as patients with hemiplegia and hip fracture and examination of quality of walking such as accuracy, form, and adaptability based on motor skill-related factors [9] may be necessary.

To conclude, we investigated differences in associations between straight and curved walking abilities of inpatients in the subacute phase according to ambulation independence levels within the ward. In the independent group, F8W and 3ZW times correlated significantly with walking velocity and cadence. In the supervised group, F8W time correlated significantly with walking velocity and stride length, but $3 \mathrm{ZW}$ time did not correlate significantly with straight walking abilities. Associations between straight and curved walking abilities varied between inpatients who could ambulate independently and inpatients requiring supervision when ambulating within the ward. These differences may depend on skill level of straight and curved walking abilities.

\section{Conflict of Interest}

The authors declared no potential conflicts of interest with respect to the authorship and/or publication of this article.

\section{References}

1. Himann JE, Cunningham DA, Rechnitzer PA, Paterson DH. Age-related changes in speed of walking. Med Sci Sports Exerc 1988;20:161-6.

2. Courtine G, Schieppati M. Human walking along a curved path. I. Body trajectory, segment orientation and the effect of vision. Eur J Neurosci 2003; 18:177-90.

3. Hess RJ, Brach JS, Piva SR, VanSwearingen JM. Walking skill can be assessed in older adults: validity of Figure-of- 8 Walk Test. Phys Ther 2010;90:89-99.

4. Masuda K, Watanabe R, Mutou M, et al. Activities of daily life in elderly, measuring the time needed to walk a 10-m zigzag. Jpn Soc Phys Educ 2004;55:421. (in Japanese)

5. Masuda S, Suganuma K, Kaneko C, Hoshina K, Suzuki T, Serita T, et al. Prediction of falls using the 3-m zigzag walk test. J Phys Ther Sci 2013;25:1050-4.

6. Odonkor CA, Thomas JC, Holt N, Latham N, Vanswearingen J, Brach JS, et al. A comparison of straight- and curved-path walking tests among mobility-limited older adults. J Gerontol A Biol Sci Med Sci 2013;68:1532-9.

7. Welch SA, Ward RE, Kurlinski LA, Kiely DK, Goldstein R, VanSwearingen J, et al. Straight and curved path walking among older adults in primary care: associations with fall-related outcomes. PM R 2016;8:754-60.

8. Salbach NM, Mayo NE, Higgins J, Ahmed S, Finch LE, Richards CL. Responsiveness and predictability of gait speed and other disability measures in acute stroke. Arch Phys Med Rehabil 2001;82:1204-12.

9. Johnson HW. Skill $=$ Speed $\times$ Accuracy $\times$ Form $\times$ Adaptability. Percept Mot Skills 1961;13:163-70. 